\title{
A LOUSA DIGITAL INTERATIVA: TÁTICAS E ASTÚCIAS DE PROFESSORES CONSUMIDORES DE NOVAS TECNOLOGIAS
}

\author{
THE INTERACTIVE WHITEBOARD: \\ STRATEGIES AND CLEVERNESSES OF THE NEW THECHNOLOGY CONSUMER \\ TEACHERS
}

\section{LA PIZARRA DIGITAL INTERACTIVA: \\ TÁCTICAS Y ASTUCIAS DE PROFESORES CONSUMIDORES DE NUEVAS TECNOLOGÍAS \\ José Adolfo Mota de Almeida Pedro da Cunha Pinto Neto ${ }^{2}$}

\begin{abstract}
RESUMO: Considerando que uma das características da sociedade atual é o maior contato com as novas mídias, principalmente na juventude, público da educação básica do século XXI, o uso de recursos audiovisuais em sala de aula pode funcionar como um elemento atrativo para os estudantes. Nesse sentido, a Lousa Digital Interativa (LDI) surge como uma ferramenta adotada por muitas escolas públicas e particulares da educação básica. Entretanto, o uso dessa nova tecnologia ainda é marcado pela seguinte contradição: se por um lado a LDI é uma ferramenta pedagógica cada vez mais presente no ambiente escolar, por outro, falta conhecer como os professores estão se apropriando dessa nova tecnologia e quais são as "estratégias, táticas e astúcias" que estão acompanhando o uso desse recurso na sala de aula. Nesse contexto, esta investigação tem como objetivo identificar como alguns professores que atuam em escolas que recentemente passaram pelo processo de implementação das LDIs em suas salas de aula estão lidando com essa nova situação. $\mathrm{O}$ aporte teórico desta pesquisa está centrado nas ideias de Michel de Certeau e as etapas consideradas para atingir esses objetivos compreenderam: entrevistas com professores de escolas públicas e particulares, que recentemente adotaram o uso das LDIs em suas salas de aula; aplicação de questionário aos outros professores da mesma rede de ensino. Ao final desse processo verificamos que, embora em realidades diversas, os docentes das diferentes escolas enfrentavam as mesmas dificuldades.
\end{abstract}

PALAVRAS-CHAVE: Tecnologia Educacional. Lousa Digital Interativa. Tecnologia da Informação e da Comunicação. Novas Mídias.

\footnotetext{
1 Mestre em Ensino de Ciências e Matemática pela Universidade Estadual de Campinas (UNICAMP). Doutorando em Ensino de Ciências e Matemática. Professor do Colégio Rio Branco em Campinas, SP - Brasil. E-mail: adolfo.mota@gmail.com

${ }^{2}$ Mestre e Doutor em Educação pela Faculdade de Educação da Universidade Estadual de Campinas (UNICAMP). Docente da Faculdade de Educação da UNICAMP, Campinas, SP - Brasil. E-mail: pcpneto@gmail.com

Recebido em: 15/06/2015 - Aprovado em: 10/08/2015
} 
ABSTRACT: Since a greater contact with the new media, especially amongst the youth who attend the $21^{\text {st }}$ century basic education, is a characteristic of our society, using audiovisual resources in the classroom can be attractive to students. A pedagogical tool called Lousa Digital Interativa (LDI - Interactive Whiteboard) has thus been adopted by many public and private schools. However, its use is marked by the following contradiction: if, on the one hand, LDI is increasingly present in school environments, on the other, we lack knowledge on how teachers are appropriating this new technology and on what "strategies, tactics and knacks" they have developed to use this resource in the classroom. Therefore, this research aims at identifying how some teachers working in schools that have recently implemented LDIs in their classrooms are dealing with this new situation. The theoretical framework of this research draws on the ideas of Michel de Certeau. Methodology included interviewing teachers of public and private schools that have recently adopted the use of LDIs in their classrooms and applying a questionnaire to other teachers of the same education network. Our results show that, although their reality differs, the teachers of these different schools are faced with the same difficulties.

KEYWORDS: Educational technology. Interactive Whiteboard. Information and Communication Technology. New Media.

RESUMEN: Considerando que una de las características de la sociedad actual es un mayor contacto con los nuevos medios, principalmente en la juventud, el público de la educación básica del siglo XXI, el uso de los recursos audiovisuales en la sala de aula puede funcionar como un elemento atractivo para los estudiantes. En ese sentido, la denominación Lousa Digital Interativa (LDI) - Pizarra Digital Interactiva - surge como una herramienta adoptada por muchas escuelas públicas y particulares de la educación básica. No obstante, el uso de esa nueva tecnología continúa marcada por la siguiente contradicción: si por un lado, la LDI es una herramienta pedagógica que está cada vez más presente en el ambiente escolar, por otro lado, falta conocer cómo los profesores se están apropiando de esa nueva tecnología y cuáles son las "estrategias, tácticas y astucias" que están acompañando al uso de ese recurso en la sala de aula. En ese contexto, esta investigación tiene como objetivo identificar cómo algunos profesores que actúan en escuelas que recientemente pasaron por el proceso de implementación de las LDIs en sus salas de aula están lidiando con esa nueva situación. El aporte teórico de este estudio está centrado en las ideas de Michel de Certeau y las etapas consideradas para alcanzar esos objetivos comprendieron: entrevistas con profesores de escuelas públicas y particulares, que recientemente adoptaron el uso de las LDIs en sus salas de aula y la aplicación de un cuestionario a otros profesores de la misma red de enseñanza. Al final de ese proceso verificamos que, a pesar de las diversas realidades, los docentes de las diferentes escuelas enfrentaban las mismas dificultades.

PALABRAS-CLAVE: Tecnología Educacional. Pizarra Digital Interactiva. Tecnología de Información y Comunicación. Nuevos Medios.

\section{INTRODUÇÃO}

As novas tecnologias da informação e comunicação (TICs) já fazem parte da vida de muitas pessoas. A cada dia, o uso dessas ferramentas difunde-se pelos diversos ramos da sociedade, transformando de maneira significativa o cotidiano das famílias, dando celeridade à circulação de informações e, em muitos casos, facilitando a comunicação. Frequentemente, somos surpreendidos com novidades no mercado de aparelhos eletrônicos, com o lançamento de novos aplicativos, novas redes sociais e com uma infinidade de jogos que a cada versão apresentam novas ferramentas e qualidades gráficas até então inimagináveis. Muito se tem falado dos benefícios gerados com o desenvolvimento das novas tecnologias, mas ainda é muito incipiente o debate acerca dos problemas que surgiram com a evolução técnica, como nos relatava Lévy. 


\begin{abstract}
$\mathrm{Na}$ época atual, a técnica é uma das dimensões fundamentais onde está em jogo a transformação do mundo humano por ele mesmo. A influência cada vez mais impregnante das realidades tecnoeconômicas sobre todos os aspectos da vida social, e também os deslocamentos menos visíveis que ocorrem na esfera intelectual obrigam-nos a reconhecer a técnica como um dos mais importantes temas filosóficos e políticos de nosso tempo. Ora, somos forçados a constatar o distanciamento alucinante entre a natureza dos problemas colocados à coletividade humana pela situação mundial da evolução técnica e o estado do debate "coletivo" sobre o assunto, ou antes do debate midiático (LÉVY, 1993, p. 7).
\end{abstract}

Para Nakashima (2008), a proliferação de dispositivos eletrônicos na atual sociedade da informação permite maior mobilidade, personalização e conectividade aos usuários. Nessas condições, as TICs ganham força, principalmente, na comunicação entre as pessoas por meio de mensagens eletrônicas e videoconferências. Cabe recordar, por exemplo, a recente expansão das redes sociais e dos usuários de serviços gratuitos de correio eletrônico. É graças à facilidade com que essas tecnologias atingem as pessoas que os usuários da internet e da telefonia celular compreendem um dos mais importantes mercados consumidores de telecomunicação no mundo atual. Essas novas mídias constituem um gigantesco mercado de negócios e suas ferramentas seduzem cada vez mais uma crescente legião de consumidores.

Por causa do papel central que essas novas mídias desempenharão no desenvolvimento deste trabalho, faz-se necessário definir o termo. Afinal, o que são novas mídias? Para Manovich (2001), podemos começar a responder essa questão listando uma série de tecnologias que são popularmente reconhecidas como novas mídias, por exemplo: software em geral, internet, sites, realidade virtual, vídeos digitais, jogos computacionais, arquivos digitais, lousas digitais etc.

Todos esses exemplos têm uma característica em comum: eles necessitam do computador para produção, exibição e distribuição. Nesse sentido, um texto digital é considerado uma nova mídia, enquanto que o texto impresso não. Do mesmo modo, um vídeo digital consiste numa nova mídia, enquanto que o vídeo em fita magnética não se enquadra nessa categoria.

Em suma, todas as TICs que podem ser consideradas novas mídias são constituídas por dados que podem ser computáveis, ou seja, dados de natureza numérica acessível por meio do computador. Essas características implicam no fato de que as novas mídias permitem a interatividade, pois são compostas de códigos digitais representados por funções matemáticas cujos algoritmos podemos manipular (MANOVICH, 2001).

A história das mídias modernas está intimamente ligada à história dos computadores. Esse elo pode ser explicado pelo fato do desenvolvimento tecnológico de ambos ter acontecido concomitantemente. Acresce que em muitos casos, o desenvolvimento dos computadores serviu como suporte para o desenvolvimento de novas mídias e vice-versa. Essas conexões ocorrem, por exemplo, quando um programador utiliza um computador para \begin{tabular}{l|l|l|l|l|l|l|l|} 
(C) ETD - Educ. temat. digit. & Campinas, SP & v.17 & n. 2 & p.394-413 & maio/ago. 2015 & ISSN 1676-2592
\end{tabular} 
produzir um novo software. Assim como quando um desenvolvedor de hardware utiliza um software para projetar um novo componente para computadores.

De certa forma, todo esse desenvolvimento tecnológico que vivenciamos no mundo atual e que vem deslocando nossa sociedade na direção de um novo paradigma sociotécnico, surgiu durante a revolução tecnológica na década de 1970, considerada por muitos como um divisor tecnológico. Constitui um período no qual podemos destacar inúmeros avanços tecnológicos que foram fundamentais para que pudéssemos chegar ao atual estágio de desenvolvimento das TICs (CASTELLS, 2000).

Inicialmente, temos em 1971 a invenção do microprocessador, que em menos de uma década estava sendo comercialmente difundido. O primeiro computador comercial de sucesso, o Apple II, começou a ser vendido em 1977, mesmo período em que a Microsoft começava a produzir sistemas operacionais para microcomputadores. Foi no início dos anos 1970 que a Corning Glass, indústria americana, começou a produzir fibras óticas em escala industrial, o que veio a colaborar amplamente com o sucesso das novas tecnologias de informação e comunicação. Nesse mesmo período, a Sony começava a produzir videocassetes comercialmente. Por último, mas não menos importante, foi em 1969 que a ARPA (Agência de Projetos de Pesquisa Avançada do Departamento de Defesa norteamericano) instalou uma rede eletrônica de comunicação que se desenvolveu durante os anos 1970 e veio a se tornar o que hoje conhecemos como internet. O desenvolvimento dessa tecnologia foi facilitado pela invenção de Cerf e Kaln, em 1974, do protocolo de interconexões em redes, o TCP/IP (CASTELLS, 2000).

Houve na década de 1970 uma grande concentração temporal e espacial de feitos notáveis no campo das TICs, pois foi nesse período que a Califórnia, nos Estados Unidos, tornou-se o mais importante centro desenvolvedor. Favorecidos por inúmeros incentivos institucionais, econômicos e culturais, os Estados Unidos protagonizaram essa grande revolução tecnológica.

Ainda segundo Castells (2000), esse novo paradigma sociotécnico foi delineado pelo contexto histórico em que se expandiu, pois na década de 1980, o capitalismo passou por uma reformulação na qual as novas tecnologias da informação desempenharam papel fundamental e foram decisivamente moldadas por esse mesmo papel. Exemplo disso foi o desenvolvimento, nos anos 1980, de grandes empresas no ramo das telecomunicações, o que possibilitou a integração global dos mercados financeiros e a articulação segmentada da produção e do comércio mundial.

Essas tecnologias forçaram mudanças significativas nas sociedades. Elas moldaram a nossa forma de nos comunicar, reinventaram o nosso cotidiano e funcionam quase que como uma extensão do nosso corpo. E, a cada evento de surgimento de novas tecnologias, a sociedade modifica-se (GARCÍA; FERNANDEZ; SOUZA, 2011). 
Nesse contexto, é de se esperar que as tecnologias que permeiam todos os segmentos da sociedade influenciem também o ambiente escolar. Em um número crescente de escolas, o uso de ferramentas tecnológicas, como o computador, o projetor de multimídias, a internet, a LDI, entre outras, já fazem parte do cotidiano. Além disso, é cada vez maior o número de alunos e professores com acesso a uma variada gama de dispositivos digitais. De acordo com Silva (2003, p.75), "nenhum setor da sociedade - mesmo aqueles tradicionalmente resistentes ou menos adeptos às inovações - parece ficar imune às incidências das novas tecnologias. Exemplo claro disso é o setor da educação".

Alguns dados podem nos ajudar a compreender a influência das tecnologias na sociedade brasileira atual. De acordo com dados coletados em 2012 pelo Centro de Estudos Sobre as Tecnologias da Informação e Comunicação (CETIC) ${ }^{3}$, um total de $35 \%$ das residências da zona urbana brasileira tem computador de mesa, e 25\% delas têm computador portátil. Quando o assunto é telefone celular, o número é surpreendente: $90 \%$ das residências localizadas na zona urbana contam com esse tipo de aparelho.

Em contraste, os dados sobre a infraestrutura de TICs das escolas brasileiras não são tão interessantes assim. Essa mesma pesquisa aponta que somente $6 \%$ das escolas públicas brasileiras estão na lista daquelas que têm 41 computadores ou mais, sendo que nem todos esses computadores estão em pleno funcionamento. Se levarmos em consideração somente computadores funcionando, a pesquisa mostrou que apenas $3 \%$ das escolas estariam na lista.

Os dados não são muito diferentes quando o foco da pesquisa são as escolas particulares, em que somente $14 \%$ das instituições com esse perfil têm 41 computadores ou mais. Além disso, essa pesquisa relevou que menos da metade dos professores das escolas públicas e particulares usa o computador e internet para fazer pesquisas de informações com seus alunos.

Esses dados indicam que a infraestrutura ainda é uma limitação para a inserção das TICs no processo de ensino e aprendizagem e que as escolas particulares apresentam perfil semelhante aos das públicas no uso das TICs pelos alunos. Acresce que, a velocidade de conexão à internet é percebida pelos usuários como uma limitação, porque $25 \%$ das escolas tem conexão abaixo de 1Mbit/s.

Essa velocidade está abaixo da média nacional que atualmente é de 3,4 Mbit/s, como revelado em pesquisa feita pela Akamai $^{4}$ no primeiro quadrimestre de 2015. Esse mesmo estudo revelou que a velocidade média da internet no Brasil coloca o país na posição 89 no

\footnotetext{
${ }^{3}$ Criado em 2005, o Centro de Estudos sobre as Tecnologias da Informação e da Comunicação (CETIC.br) é o departamento do NIC.br responsável pela coordenação e publicação de pesquisas sobre a disponibilidade e uso da internet no Brasil. Disponível em: <http://www.cetic.br/usuarios/tic/2012/A.html>. Acesso em: 12/02/2014

${ }^{4}$ Akamai Technologies é uma empresa de internet americana, sediada em Cambridge, Massachusetts. Disponível em: <http://pt.wikipedia.org/wiki/Akamai_Technologies〉. Acesso em: 03 Ago. 2015.
} 
ranking global de velocidade média de internet, ficando aquém da média global que foi de 5,0 Mbit/s. Comparando com outros países da América Latina, a velocidade média de internet no Brasil ficou atrás da de México (4,9 Mbps), Equador (4,1 Mbps), Chile (5,7 Mbps), Colômbia (4,5 Mbps) e Argentina (4,6 Mbps) ${ }^{5}$ (BELSON, 2015).

Entretanto, alguns pequenos avanços foram observados se compararmos os dados relativos às TICs na Educação brasileira em 2010 com os dados de 2011. Por exemplo, a pesquisa do CETIC mostrou que cresceu o número de escolas com laboratório de informática, o número saltou de $81 \%$ em 2010 para $86 \%$ em 2011. Outro dado importante relevado pela mesma pesquisa de 2012 do CETIC é que $93 \%$ dos professores têm acesso à internet em casa.

Esses dados revelam que o professor está inserido num mundo em que as relações sociais e de trabalho estão cada vez mais mediadas por novas mídias (AMIEL; AMARAL, 2013). Como consequência, as TICs têm feito com que professores e outros profissionais busquem novas formas de trabalho, como declara García, Fernandez e Souza (2011, p. 96).

\begin{abstract}
As tecnologias de informação e comunicação - TIC, em todos os segmentos da sociedade, exigiram que os profissionais encontrassem novas formas de trabalho, que permitissem que os conhecimentos dos especialistas fossem aproveitados e, ao mesmo tempo, colocados em prática dentro da nova realidade, uma realidade que o mundo da comunicação e da informação impôs, um mundo em que o conhecimento pode ser acessado por muitas vias. Esse movimento de inclusão das TIC na sociedade iniciou-se primeiro no mundo empresarial, depois passou para a educação. O que precisa ser levado em conta e discutido é que o mundo empresarial é distinto da sala de aula.
\end{abstract}

Sem dúvida, o professor está no centro desse processo em que as escolas, impulsionadas por inúmeras cobranças, tentam modificar suas estruturas de modo a conseguir se adequarem às exigências do mundo mercadológico e serem reconhecidas como escolas "modernas". Para Amiel e Amaral (2013), a escola não deve se render de maneira acrítica a essas tendências e pressões, mas sempre revisitar seus princípios e buscar ser atual, uma instituição comprometida com o seu tempo e com uma projeção no futuro.

Contudo, são recorrentes na mídia popular e no meio acadêmico os discursos sugestivos que a escola deve se adaptar a essa nova realidade, ou seja, que a escola precisa se reformular para conseguir ensinar ao aluno do século XXI que são comumente chamados de "nativos digitais".

Esses discursos estabelecem uma distinção entre os "nativos digitais" (alunos), a população mais jovem que cresceu na "era digital" e por isso teriam conhecimentos sobre os usos das novas mídias que saltam aos olhos, e os chamados "imigrantes digitais"

${ }^{5}$ Disponível em: <https://www.stateoftheinternet.com>. Acesso em:03 Ago. 2015. 
(professores), que dominam a cultura letrada tradicional, mas que precisam ou optam pelo uso das práticas letradas realizadas nos meios digitais (BRAGA, 2013).

Entretanto, já encontramos diversos escritos que contestam a existência de características homogêneas entre os jovens que nasceram na era digital como vemos, por exemplo, nas afirmações de Amiel e Amaral (2013, p.2):

Apesar da aceitação do termo "nativo digital", há crescente evidência da inexistência de um grupo homogêneo de alunos no que diz respeito aos conhecimentos sobre uso de novas mídias. Mais do que isso, é possível afirmar que aqueles tradicionalmente considerados homogeneamente como "nativos" têm competências e preferências mais variadas do que a terminologia tende a indicar.

Assim também, não há como enquadrar todos os professores em uma só categoria no que diz respeito ao uso de novas mídias. Existem professores com diferentes características e tachá-los de "imigrantes digitais" não parece contribuir para compreender as relações entre professores, alunos e novas mídias.

\begin{abstract}
Quando designamos o professor como um "imigrante digital" criticamos tão somente sua falta de domínio instrumental sobre as novas mídias. Fazer uso do computador com desenvoltura ou arquitetar potencialidades com novas mídias é um traço importante da contemporaneidade, dentro e fora do ambiente escolar. No entanto, não é o domínio instrumental ou a habilidade de nomear as últimas tendências, plataformas e serviços que define a fluência tecnológica. O que desejamos com o desenvolvimento de fluência tecnológica é um pensamento mais abrangente, crítico e contextualizado, o que certamente pode ser proporcionado por alguém com menor domínio instrumental de ferramentas específicas (AMIEL; AMARAL, 2013, p.9).
\end{abstract}

Procurando compreender como esses professores estão enfrentando essa nova realidade que se impõe, foi analisado como os professores(as) do Ensino Fundamental II, da rede municipal de uma cidade do interior do Estado de São Paulo estão lidando com a implementação das LDIs em suas escolas e quais as "táticas" e "astúcias" têm empregado nas relações com essa nova tecnologia.

Além disso, procuramos ouvir professores da rede particular de ensino com o intuito de verificar se o que foi observado nas escolas municipais também ocorre em escolas particulares que, embora estejam inseridas em outra realidade, também passaram pelo processo de implementação das LDIs recentemente. 


\section{CAMINHOS PERCORRIDOS}

Nossa pesquisa manteve-se focada no ponto de vista do professor, personagem que historicamente não ocupa posição de destaque na definição das políticas educacionais. Esses profissionais, embora tenham muito a dizer, quase sempre não são ouvidos e permanecem à margem das decisões que definem suas condições de trabalho.

Exemplo disso foi observado nesta pesquisa, na qual praticamente todos os professores entrevistados afirmaram que não participaram das decisões que antecederam a implementação das LDIs em suas escolas. As decisões de implementar ou não as LDIs foram tomadas em instâncias superiores e os professores não foram ouvidos. Diante dessas imposições, "os professores criam táticas, maneiras de lidar/viver no cotidiano escolar. Num campo de lutas fazem movimentos, utilizando e manipulando as prescrições impostas" (CARRERI, 2007, p. 59).

Em conformidade com essas ideias, nesta investigação optamos por ouvir esses profissionais para compreender como se deu o processo de implementação das LDIs, pois acreditamos que os seus relatos trazem experiências, táticas e astúcias; como apontadas por Certeau (2003).

É por isso que optamos por empregar os aportes teóricos da obra de Michel de Certeau (A invenção do Cotidiano:1. Artes de fazer), na qual o autor apresenta os resultados de uma vasta pesquisa que foi realizada nos anos 1970 sobre os problemas de cultura e a sociedade (CERTEAU, 2003). A escolha desse autor se fundamenta no fato de que ele tem o olhar voltado para aqueles que, como esses professores, não estão em posição de destaque na sociedade. Porém, acreditamos que "esses sujeitos comuns, os homens ordinários, possuem relatos de experiências significativas" (CARRERI, 2007, p.13).

Algumas das ideias traçadas por Certeau ajudaram a compreender as táticas empregadas pelos professores para adaptar suas práticas pedagógicas, ao serem impelidos a utilizar a LDI em suas aulas, assim como para compreender as práticas pelas quais eles se reapropriam do espaço organizado pelos gestores do sistema de ensino.

Essas táticas adotadas por eles em situações diversas refletem as astúcias desses consumidores de tecnologias para burlar as regras oriundas de instâncias superiores e moldálas ao seu jeito e gosto, fazendo o que esse autor classifica de práticas consumidoras. É durante a prática consumidora que os "sujeitos praticantes dão sentido às suas existências engendrando artes de fazer como lances de um jogo, que reconfiguram, inventam e transformam estratégias produzidas pela ordem instituída" (ROSA; CARRERI; RAMOS, 2012, p. 107-108). 
Essas ideias de Certeau nos ajudaram a compreender como os professores reagiram diante da imposição do uso das LDIs. Elas funcionaram como suporte que permitiram identificar como esses profissionais buscaram maneiras de subverter as imposições feitas pelo poder institucional, maneiras de empregar os produtos impostos por uma ordem econômica dominante. Essas relações que os professores estabelecem com tais imposições se enquadram no que Certeau qualifica de "consumo".

Essas formas de resistências e relações de disputa que podem ser observadas no uso das tecnologias pelos professores, também são descritas por Certeau em algumas etnias indígenas:

\begin{abstract}
Há bastante tempo que se tem estudado que equívoco rachava, por dentro, o 'sucesso' dos colonizadores espanhóis entre as etnias indígenas: submetidos e mesmo consentindo na dominação, muitas vezes esses indígenas faziam das ações rituais, representações ou leis que lhes eram impostas outra coisa que não aquelas que o conquistador julgava obter por elas. Os indígenas as subvertiam, não rejeitando-as diretamente ou modificando-as, mas pela sua maneira de usá-las para fins e em função de referências estranhas ao sistema do qual não podiam fugir (CERTEAU, 2003, p. 39).
\end{abstract}

Michel de Certeau relata como esses indígenas, que não tinham meios para recusar o poder do dominador, escapavam sem deixá-los. A força de sua diferença se mantinha nos procedimentos de consumo. "Em grau menor, um equívoco semelhante se insinua em nossas sociedades com o uso que os meios 'populares' fazem das culturas difundidas e impostas pelas elites produtoras de linguagem” (CERTEAU, 2003, p.40).

Assim como os indígenas, os professores consumidores de tecnologias, embora em outro contexto, também utilizaram em suas práticas cotidianas, procedimentos que "curtocircuitam" as determinações institucionais. Essas práticas compreendem as formas como esses professores se reapropriam do espaço organizado por uma rede de "vigilância" segundo seus interesses próprios e suas regras próprias (CERTEAU, 2003).

Esses escritos de Certeau vão de encontro à situação vivida pelos professores e permitem compreender como esses sujeitos comuns, os homens ordinários da vida escolar, vivem em uma rede de relações com o mundo, empregando táticas para sobreviver. Isso se aproxima do que Michel de Foucault propõe sobre a ideia de relações de poder. Para Foucault, o poder não está nas mãos de uma única instituição, não está apenas de um lado. Existem relações de poder e esse poder está disseminado, em tudo e em todas as pessoas (CARRERI, 2007).

Na prática docente, o cotidiano da sala de aula permite ao professor modificar esse espaço, um território projetado e pensado por outro, mas que por um determinado período está sob o comando desse profissional, e ele o faz à maneira de um apartamento alugado, ele 
transforma a propriedade do outro em lugar tomado de empréstimo, mas por um tempo determinado (CERTEAU, 2003).

\begin{abstract}
O "apartamento alugado" é repleto de sentimentos e experiências, pois representa como as pessoas se apropriam de "coisas" e com astúcias dão sentido próprio àquilo que é do outro. Assim, vão modificando ao seu interesse, da maneira que mais lhe agrada, como um apartamento alugado, que as pessoas mobíliam o que é do outro a seu gosto (CARRERI, 2007, p.62).
\end{abstract}

De modo geral, este trabalho empregou os conceitos e metáforas apresentados nessa introdução para analisar os dados coletados durante a pesquisa. Para isso, procuramos ouvir os relatos dos docentes que enfrentaram dificuldades ao passarem pelo processo de implementação das LDIs em suas escolas.

A escolha de "garimpar" nas falas desses professores os dados dessa investigação se coaduna com as ideias defendidas por Certeau de uma pesquisa centrada nos sujeitos que não ocupam posição de destaque na sociedade. Dessa forma, o foco desta pesquisa não está na tecnologia em si, mas sim nas experiências dos docentes com essa tecnologia.

\title{
3 A LOUSA DIGITAL INTERATIVA
}

No final do século XIX o uso do quadro-negro começa a ser difundido nas escolas e assume o papel de tecnologia central na sala de aula, período em que lentamente consolidamse os sistemas públicos de instrução elementar e, paralelamente, crescem as exigências de um mínimo de mobiliário e material escolar (BASTOS, 2005).

\begin{abstract}
As vantagens do quadro-negro residiam na possibilidade de o professor utilizar-se desse dispositivo para o ensino simultâneo das primeiras lições de leitura e de escrita. O quadro-negro para o professor e a lousa para o aluno eram meios pelos quais seria conhecido o alfabeto e seriam desenhadas as letras. Além disso, era um excelente meio de ensinar em pouco tempo os alunos a ler e escrever. Um auxiliar indispensável para a lição oral, um suporte de escrita - 'um ritual diário de escrita para fixar discursos e práticas pedagógicas’ (CHARTIER, 2002 apud BASTOS, 2005, p.136).
\end{abstract}

Ao longo do século XX, o quadro-negro vai sendo gradualmente modificado, muda sua textura e passa a ser verde ou azul, mas continua mantendo sua centralidade no processo de ensino-aprendizagem. As modificações continuam no século XXI e o quadro que foi negro e tornou-se colorido, agora ficou branco. Além disso, nesse mesmo período, surgem as LDIs que trazem novas ferramentas digitais e aparecem nas escolas como sinônimo de modernidade, mas embora o número desse equipamento seja cada vez maior, é preciso pesquisar qual é a contribuição das LDIs no processo de ensino-aprendizagem. Contudo, ainda não há um consenso de como avaliar os usos que são feitos dessas tecnologias e suas aplicações didáticas. 
A Lousa Digital Interativa é um equipamento tecnológico cada vez mais conhecido, e as instituições de educação investem na aquisição do equipamento. $\mathrm{Na}$ Espanha, por exemplo, as universidades já possuíam 1056 Lousas Digitais Interativas em Junho de 2009, o que significava 21,8 lousas por universidade. Foi um incremento de $50 \%$, em comparação com dados de dois anos anteriores. O crescimento da quantidade de equipamentos disponíveis aos educadores tem importância, mas, além de conhecer e valorizar a potencialidade dos recursos que a lousa digital oferece, é fundamental pesquisar se esses recursos podem ajudar ao professor a ensinar. No entanto, ainda não há um método oficial para uma avaliação dos usos e das aplicações didáticas (GARCÍA; FERNANDEZ; SOUZA, 2011, p.94).

Basicamente, podemos dividir as tecnologias encontradas no mercado em duas categorias: Lousas Digitais Interativas e Projetores Interativos (PIs). A LDI consiste numa tela conectada a um computador e é utilizada em conjunto com um projetor de multimídias. Além disso, os modelos mais comuns no mercado utilizam um software responsável pela troca de informações entre o computador e a LDI. Além disso, as LDIs necessitam de uma tela sensível ao toque do dedo ou da caneta. Já os PIs têm o princípio de funcionamento muito parecido com o das LDIs, mas esses equipamentos prescindem de tela sensível, sendo possível utilizar qualquer superfície.

As características de funcionamento das LDIs variam de acordo com o fabricante, mas de modo geral, consistem numa tela capaz de reconhecer o toque ou a outro movimento mimético natural, e suas formas de captar os comandos podem variar de acordo com o fabricante, mas, de modo geral, são utilizadas as formas ultrassônica, resistiva, eletromagnética ou infravermelha.

Além disso, a LDI permite a execução de softwares, pode funcionar em associação a ferramentas multimídias e dispõe de dimensões suficientes que permitem a apresentação de conteúdo a um grupo de pessoas. Nela, as imagens apresentadas são carregadas de um ou mais computadores e podem ser comandadas por uma ou mais pessoas com suas funções específicas diretamente na tela (GARCÍA; FERNANDEZ; SOUZA, 2011, p. 98).

Em suma, não se pode negar que a LDI tem recursos que podem colaborar com o processo de ensino-aprendizagem. No entanto, muitas das tarefas que são feitas por meio das LDIs podem ser realizadas empregando outros recursos por vezes mais baratos. Sendo assim, muitas vezes os recursos são subutilizados e a novidade tecnológica chega a ser um empecilho para o bom andamento das aulas.

\section{PAISAGENS AVISTADAS}

Este trabalho é parte de uma dissertação de mestrado. Os dados aqui apresentados foram coletados num município do interior do Estado de São Paulo, no qual em 2008 foram instaladas LDIs nas salas de aula do Ensino Fundamental II. A escolha dessa cidade foi determinada levando-se em consideração alguns aspectos: em primeiro lugar, a presença das \begin{tabular}{ll|l|l|l|l|l|l|} 
(c) ETD - Educ. temat. digit. & Campinas, SP & v.17 & n. 2 & p.394-413 & maio/ago. 2015 & ISSN 1676-2592
\end{tabular} 
LDIs nas salas de aula; em segundo lugar, o fato de alguns professores aceitarem participar da pesquisa dando entrevistas e respondendo a questionários e, por último, a localização da cidade que favoreceu a coleta de dados.

Neste município as lousas foram instaladas em todas as escolas do Ensino Fundamental II (do $5^{\circ}$ ao $9^{\circ}$ ano) da rede pública, que somam um total de seis unidades. Essas escolas contam com 43 salas de aulas que atendem cerca de 3400 alunos. Além disso, os professores podem reservar um computador para cada aluno e desenvolver atividade com o uso da LDI e do computador concomitantemente. Os alunos do $1^{\circ}$ ao $5^{\circ}$ ano não têm acesso às LDIs na sala de aula, mas podem desenvolver atividades com o equipamento no laboratório de informática.

A primeira etapa da pesquisa de campo consistiu em entrevistar um professor desse município a quem chamaremos pelo pseudônimo de John. Esse professor tem três graduações, ele é formado em Ciências, Matemática e Pedagogia. Tem especialização em gestão educacional, já foi diretor de escola, supervisor da Secretaria de Educação do município e lecionou no Ensino Superior. John atua como docente há mais de 15 anos e tem ampla experiência em sala de aula e nos cargos de gestão.

A escolha de John foi determinada pelo fato de ele aceitar participar da pesquisa, mas principalmente, por ter um duplo olhar acerca das LDIs. John era supervisor de ensino da Secretaria Municipal de Educação quando as lousas digitais chegaram naquelas escolas e no momento da pesquisa estava acompanhando o processo de implementação das LDIs da sala de aula como professor. Sendo assim, ele tem um olhar de dentro e um olhar de fora:

Quando ocorreu essa implementação eu não estava na sala de aula, eu era supervisor de ensino da secretaria; então, eu acompanhei essa implementação de um outro lado. Não do lado mais pedagógico, mas sim do lado administrativo. (...) agora não sou mais supervisor, sou professor. (John)

Grande parte das perguntas feitas ao entrevistado foi direcionada para conhecer o ponto de vista dele sobre o uso das LDIs no cotidiano das escolas.

John e os seus colegas de trabalho são os responsáveis por colocar em prática as políticas educacionais adotadas pelos órgãos gestores, ou seja, o sucesso da implementação de novas ferramentas tecnológicas no processo de ensino-aprendizagem passa pelos agentes executores dessas políticas, que neste caso são os professores. Contudo, esses atores, geralmente, não são convidados a participar das decisões.

Durante a entrevista, o professor John nos relatou como surgiu a ideia de instalar as LDIs nas escolas e como ocorreu a capacitação inicial dos docentes. 
Então, na verdade, foi uma ideia do município de implantar uma lousa digital em cada sala de aula do município todo, do sexto ao nono ano, e um classmate, um netbook, para cada aluno. E aí foi feito um convênio, uma parceria com o Positivo apostilado, Sistema de Ensino Positivo. Para isso os professores tiveram uma capacitação inicial, e essa capacitação foi voltada mesmo para as ferramentas da lousa, por exemplo: o que significa cada comando. $\mathrm{Na}$ verdade, foi mais instrumental do que pedagógico. (John)

A entrevista com John forneceu informações que nos ajudaram a elaborar um questionário on-line ${ }^{6}$, desenvolvido utilizando a plataforma Google. O questionário foi respondido por um grupo de oito professores, continha 21 itens, entre os quais questões objetivas e dissertativas.

As questões elaboradas podem ser divididas em três categorias: as que objetivavam traçar o perfil dos professores entrevistados, questões que pretendiam identificar como o entrevistado utilizava a LDI e questões direcionadas a compreender as condições de uso da LDI.

Como não foi concedida a autorização para a entrada nas escolas, o questionário foi enviado a um grupo de professores do município, dos quais oito se disponibilizaram a respondê-lo. Junto com o questionário foi enviado um termo que esclarecia seus objetivos e os da pesquisa em desenvolvimento.

Assim, um aspecto fundamental do projeto de pesquisa foi conservado, o da ideia de direcionar o nosso olhar para a figura do professor, o qual costumeiramente não é chamado a participar das decisões que influenciam diretamente no processo de ensino-aprendizagem.

Nessa perspectiva, a investigação não objetivou focar as atenções nos gestores que elaboraram as políticas de implementação das LDIs para as escolas pesquisadas, mas sim nos professores que de fato são os responsáveis pelo desenvolvimento de tais políticas no cotidiano das escolas.

Após concluirmos essa primeira etapa da coleta de dados, realizamos o mesmo procedimento em uma escola particular, ou seja, entrevistamos uma professora da escola e com base nas informações da entrevista elaboramos um questionário - também on-line - que foi respondido por outros professores da mesma escola. Como a entrevista revelou condições muito parecidas com aquelas encontradas nas escolas públicas, não houve a necessidade de elaborar um novo questionário e o instrumento de coleta de dados foi o mesmo.

Para preservar a identidade da professora entrevistada, vamos chamá-la pelo pseudônimo de Janis. Ela é formada em Matemática, atua na rede particular exclusivamente desde 1976, ou seja, tem uma experiência de 38 anos ministrando aulas de matemática e

6 O questionário utilizado na pesquisa pode ser visualizado no seguinte endereço eletrônico: <https://docs.google.com/forms/d/1UG4yaMvloYUPFLUw9g8GH85Y2UFpQVQTtBhXYfu1nds/viewform>. Acesso em: 03 Ago. 2015. 
geometria. Embora já tenha lecionado em diferentes níveis de ensino, nos últimos 20 anos ela tem atuado somente no Ensino Médio.

Em 2006, a escola em que Janis trabalha passou por mudanças significativas na estrutura tecnológica das salas aula com a instalação das LDIs. A professora vivenciou todo o processo de implementação das LDIs e conhece com detalhes as dificuldades que os professores enfrentam diariamente para usar a nova ferramenta. De maneira semelhante ao que aconteceu na escola pública estudada, na escola em que Janis trabalha, a maioria dos professores também não participou das decisões que antecederam a instalação dos equipamentos nas salas de aula, como nos relatou a professora.

Não, elas vieram prontas. Na primeira vez que surgiu a Lousa (LDI) a gente teve um treinamento, depois as lousas (LDI) foram "pipocando", aparecendo e a gente foi se virando. (Janis)

Essa segunda parte da pesquisa não teve como objetivo principal comparar as escolas, mas sim o de olhar para as duas realidades. Contudo, os dados revelaram que muitos dos problemas enfrentados pelos docentes da rede pública aparecem também no cotidiano da escola privada pesquisada.

No total, 13 professores responderam o questionário, sendo oito da rede pública e cinco da rede particular. A pesquisa contou com professores de diferentes disciplinas e faixa etária. Cada professor(a) recebeu um pseudônimo com a intenção de preservar o anonimato.

Apesar do número de respondentes, acreditamos que a quantidade de participantes não constitui um fator que diminui a qualidade dos dados, pois não buscamos trabalhar com informações baseadas na distribuição normal.

Acreditamos que os relatos dos professores constituem fontes confiáveis e representam uma tentativa de "resistência frente aos métodos tradicionais da história, que são extremamente marcados pela legitimidade em torno das chamadas fontes primarias, como documentos, textos, registros sempre na forma escrita" (CARRERI, 2007, p. 69).

Os professores que participaram da pesquisa lecionam disciplinas variadas, mas todos têm mais de 30 anos de idade. De todos os participantes, o professor Milton é o com menor tempo de magistério e o professor Hermeto é o que tem a mais longa carreira docente.

Esses professores convivem com determinações elaboradas pela Secretaria Municipal de Educação e direções pedagógicas para que o uso das LDI seja efetivado. A proposta original da Secretaria Municipal de Educação, por exemplo, era de fazer uma transição gradual para a nova forma de ensino, seguindo a seguinte estratégia: $40 \%$ do conteúdo seriam dados diretamente por meio dos Classmates PC, 60\% por meio dos métodos tradicionais 
(livros, cadernos etc.) e $100 \%$ do que fosse ensinado deveria passar pela lousa digital (MATTAR, 2013).

Quando perguntamos aos professores se eles participaram das decisões que antecederam a chegada das LDIs nas escolas, dos 13 participantes, somente cinco disseram que sim, todos os outros responderam não. Esse dado confirma o que tem acontecido com frequência quando o assunto é a implementação de novas tecnologias aplicadas à educação. Quase sempre o professor não é consultado e as decisões ficam a critério dos gestores. Esse quadro vai ao encontro das afirmações feitas por García, Fernandez e Souza (2011, p.97):

Na educação, buscam-se práticas apropriadas para o uso de tecnologias em sala de aula e para a formação dos professores, mas quase nunca se pergunta ao professor quais são as suas verdadeiras necessidades. Quais as questões que são realmente pertinentes para o processo de ensino e aprendizagem com o uso de TIC?

No entanto, embora a maioria dos docentes não tenha participado das decisões que antecederam a chegada das LDIs, as solicitações feitas pelas instituições para que os professores utilizem as novas mídias é bem vista por grande parte deles. Os dados revelam que muitos concordam que deve haver pressão para que o uso da ferramenta seja mais efetivo, enquanto outros são mais cautelosos e acreditam que deveria haver um planejamento mais adequado, como podemos perceber, por exemplo, na fala do professor Hermeto.

Houve (Solicitação), quando da implantação das lousas, que entraram como qualquer modismo tecnológico nas salas de aula. A solicitação vinha da seguinte maneira: "Agora que compramos, precisamos usar". Penso que toda a adoção de toda parafernália tecnológica (lousas, tablets etc.) veio sem muita reflexão sobre a real utilidade pedagógica e auxílio ao professor para orientar na prática. Sempre que surge algo novo, há muito barulho em torno da "revolução" que esse "novo" significa. Isso é fomentado pelos detentores da tecnologia. Mas seria preciso, antes, medir o impacto real das novas tecnologias nas práticas pedagógicas e no sucesso da aprendizagem dos alunos. (Hermeto)

Em sua fala, Hermeto demonstra preocupação com os impactos que as mudanças tecnológicas teriam na aprendizagem dos alunos. De acordo com o professor, esse aspecto não foi debatido em sua escola antes da chegada das LDIs.

O professor Milton afirma que há uma solicitação, mas que essa ocorre sem nenhuma pressão.

Sim. Acontece de forma natural, sem nenhuma pressão. Acredito que é justo, é um investimento por parte do colégio, e para o professor é uma ótima ferramenta. (Milton)

Para o professor John, a pressão exercida pela direção existe por causa do alto custo dos equipamentos instalados. 
Sem dúvida. Há ainda (Pressão). Na verdade, (...) tem essas coisas. Eu não participo dessa parte financeira, mas deve ser um investimento alto e como as escolas já tinham lousa convencional, essas lousas digitais foram afixadas bem no meio da lousa (convencional) e a lousa anterior ficou por detrás delas (LDIs); então, tem um tantinho de lousa para um lado de cá e um tantinho para o lado de lá e é proibido utilizar giz, apagador. Dizem que o pó do giz danifica a lousa digital... não sei se é verdade ou se é um tipo de pressão velada ... não é? Mas o que acontece é assim: noventa por cento, que eu percebo; eu posso estar exagerando, mas a maioria das vezes você tem o computador, aí aparece aquela tela da lousa e você com o canetão faz aquilo como se fosse uma lousa (convencional), entende? Só mudou do giz para caneta especial e para aquele material. Você vê professores passando textos, corrigindo atividades ali... entende? Então, na verdade, não sei se isso modificou a dinâmica. Claro, você tem acesso à internet, por exemplo, logo você pode passar um vídeo, você ... a visualização melhor para os alunos, mas não acredito que tenha melhoria... até no rendimento dos alunos. (John)

Ele ainda acrescenta detalhes de como ocorreu o processo de supressão da lousa tradicional e quais foram as estratégias empregadas pela Secretaria de Educação para forçar os professores a usar somente a LDI. Segundo John, ninguém poderia utilizar a lousa tradicional por causa do fato de que a LDI, de maneira simbólica, ter sido afixada à frente da lousa antiga. Vemos aqui o novo se sobrepondo ao velho, percebemos uma estratégia bem definida dos dirigentes para obrigar os docentes a utilizar a LDI.

Além disso, a alegação de que o giz danifica o equipamento, coloca os professores que queiram utilizar a lousa tradicional numa posição que, de certa forma, os aproxima de alguém que está fazendo algo que não é "correto".

Entretanto, John também nos revela as táticas usadas pelos docentes nesse caso. Segundo o entrevistado, a maioria dos professores utiliza a LDI como faziam com a lousa tradicional, eles subverteram as determinações da Secretaria de Ensino com suas táticas e astúcias. O uso está acontecendo como foi determinado pela direção pedagógica, mas esse uso é o mesmo que acontecia com a lousa tradicional. Essas "maneiras de fazer" constituem as mil práticas pelas quais usuários se reapropriam do espaço organizado pelas técnicas da produção sociocultural (CERTEAU, 2003).

Uma situação muito parecida foi observada no depoimento da professora Janis que leciona na escola particular. Ela nos relatou que a direção pedagógica da escola sempre solicitou que os professores utilizassem as LDIs.

A direção sempre solicitou que a gente utilizasse a lousa (LDI), sempre, acho que condição para ter o material que ele fosse utilizado. (Janis)

Contudo, alguns aspectos do funcionamento do equipamento, a falta de manutenção e a capacitação ineficiente fizeram com que a professora se sentisse insegura para usar a ferramenta e classificasse como uma grande tristeza o sentimento experimentado por ela nos momentos em que precisa fazer algo diferente durante o uso do equipamento. A profissional, 
inclusive, assume que a culpa pode ser dela por não ter os conhecimentos que julga necessários para utilizar a LDI. A professora se apega a um argumento geracional para justificar tais dificuldades. Entretanto, ela nos relata que os próprios alunos têm dificuldades de lidar com as LDIs.

Houve uma capacitação lá em 2006 quando foi implantada a primeira lousa (LDI), depois não teve mais nada, aí a gente foi aprendendo ensaio e erro... Na frente dos alunos, aquela situação constrangedora. Após o primeiro treinamento a gente pegou a lousa(LDI) e trabalhou sozinho. Então corresponder às expectativas foi quase zero. Além disso, para você abrir a caixa de ferramentas, pra você utilizar, para você montar(...) a hora que você olha para a classe você tem que trazer os alunos de volta (...) eles perdem a concentração totalmente. Bastou você se perder na lousa (LDI) que você perdeu a classe. Então isso para mim é a grande tristeza para eu usar esse material (LDI). Pode ser até a falha minha de não ter uma agilidade para mexer com a questão da informática, minha geração tem muito mais dificuldade do que a sua geração (Entrevistador), que acaba tendo muito mais dificuldade que a geração dos alunos, mas de vez em quando os alunos pegam a lousa (LDI) para abrir alguma ferramenta e eles também se perdem. As lousas (LDIs) não são ágeis, não são feitas para facilitar a sua vida, elas são feitas para te desafiar. Por isso que para mim é um desafio toda vez que eu tenho que fazer algo que foge ao padrão. (Janis)

Uma situação muito semelhante aconteceu na rede pública. O professor John deu detalhes sobre o curso de capacitação que os professores receberam.

Não houve um acompanhamento no sentido de como utilizar pedagogicamente. Foi algo mais geral. Daí, aconteceram alguns encontros durante o primeiro ano de implementação, uma vez por bimestre, ou uma vez por semestre, eu não me lembro exatamente, mas teve essa preocupação de instrumentalizar os professores. (...) Foi muito rápido! "Olha, isso aqui serve para isso e isso daqui serve para aquilo". Foi dar o manual mesmo, ao invés de você entregar para o professor um manual sobre o que a lousa (LDI) tem e faz, foi uma pessoa que falou. (John)

John deixa claro em seu depoimento que a capacitação inicial foi mais instrumental do que pedagógica; não houve preocupação de discutir com os docentes as possibilidades de uso da ferramenta do ponto de vista de cada disciplina. De acordo com ele, foi uma capacitação rápida que se preocupou em apresentar aos professores como a LDI funciona do ponto de vista técnico.

A falta de um curso de capacitação que atenda as demandas dos docentes pode funcionar como um fator que impulsione os professores a adotarem táticas. Esses cursos de formação que pouco auxiliam o professor a enfrentar os desafios encontrados na sala de aula nos remetem aos escritos de Amiel e Amaral (2013, p. 2). 


\begin{abstract}
Os cursos de formação continuada têm sido alvo de maior atenção pelos investigadores da área educacional, apesar dos reduzidos impactos que costumam gerar e do alto custo de implementação (...). Estes cursos são usualmente curtos e enfatizam a manipulação de ferramentas, principalmente do computador, apresentando recomendações de como e onde utilizar planilhas e editores de textos. (...) Explicações instrumentais e simplistas pouco iluminam o escopo do que se constitui a tecnologia. Menos ainda é o apoio desses cursos diante de um desafiador contexto escolar e da complexidade de práticas que envolvem os usos das novas mídias fora ou dentro da sala de aula.
\end{abstract}

A falta de um curso de formação adequado leva os professores inseguros diante das novas mídias a adotar táticas para driblar as dificuldades. A professora Janis conta como ela enfrenta esses obstáculos.

Eu fecho a lousa digital, vou para lousa de giz e dou a minha aula e os alunos adoram, porque eu não fiquei mais irritada, estou tranquila. Você tem o recurso na lousa com giz de utilizar cores, de ir e voltar na resolução de exercícios e exposição de conteúdo. Então eu acho, particularmente, que o aluno acha bonito ter a lousa digital, mas o que o aluno mais gosta é de giz e lousa ainda. (Janis)

Assim como acontece na escola pública, a professora utiliza as falhas do próprio sistema para justificar o uso que ela faz da lousa tradicional, ou seja, a falta de manutenção e a capacitação ineficaz desembocam no uso de táticas que forçam a professora a ministrar suas aulas da maneira que sempre considerou mais eficiente. Essas táticas e astúcias constituem maneiras de sobreviver diante das dificuldades cotidianas e a professora se diz mais tranquila e menos irritada quando trabalha do modo que sempre fez e que segundo ela os alunos adoram.

Nos casos de John e Janis, as instituições cobram o uso da LDI, mas os professores com suas maneiras de fazer empregam táticas no cotidiano escolar e fazem o uso do equipamento da maneira que lhes parece mais conveniente. Essas escolhas nos remetem, novamente, à ideia de apartamento alugado. Esses movimentos "minúsculos" nos revelam como os mecanismos da disciplina impostas pelas instituições são curto-circuitados por meio de táticas que demonstram um descontentamento dos professores com a forma que o uso das LDIs é imposto. É certo que muitos docentes, praticantes do cotidiano escolar, podem não ter uma visão de todo o conjunto de procedimentos que formam as táticas por eles mesmos praticadas, mas com certeza todos conseguem perceber os benefícios dessas práticas, ou seja, suas aulas não param e eles conseguem cumprir as tarefas do dia a dia.

Cabe aos "praticantes ordinários da vida cotidiana" escolher a que lance recorrer em cada ocasião, praticantes esses que, servindo-se de táticas, não enxergam o jogo em sua totalidade, mas transformam o cotidiano por meio do consumo ativo (uso), produzindo suas “maneiras de fazer" (ROSA; CARRERI; RAMOS, 2012, p.108).

As ideias de Certeau e as falas desses professores nos fornecem uma ideia do cenário no qual eles estão inseridos. É nesse ambiente repleto de disputas que os 
consumidores/professores fazem movimentos, utilizando e manipulando as prescrições impostas pelas instituições (CARRERI, 2007).

\section{CONCLUSÕES}

A pesquisa aqui apresentada revelou que o processo de implementação das LDI nas escolas estudadas foi marcado pela falta de diálogo entre direção pedagógica e professores. Em todas as escolas que participaram da pesquisa, os professores, de modo geral, não participaram das decisões que definiram a adoção do novo dispositivo. Esses profissionais tiveram de incorporar em suas aulas uma ferramenta que não foi escolhida por eles.

No entanto, apesar de não terem sido consultados, não percebemos nas falas dos professores uma resistência declarada ao uso das LDIs. Muito professores, inclusive, dizem apreciar os recursos encontrados na nova ferramenta. Essa constatação pode estar associada ao fato de a coleta de dados ter sido feita mais de cinco anos após a instalação dos equipamentos. Dessa forma, houve tempo suficiente para que a maioria dos docentes passasse por um período de adaptação, de modo que agora suas falas possuem um tom de aceitação.

Entretanto, essa aceitação não representa passividade. A pesquisa indicou que o ambiente da sala de aula consiste num espaço de disputa silenciosa, onde os professores, com suas maneiras de fazer, criam táticas para sobreviver diante das imposições feitas pelas instituições que exercem o poder.

De certa forma, a pesquisa revela a ausência de reflexão sobre o papel pedagógico/didático da LDI. Afinal de contas, por que foram colocadas na sala de aula? Fica a sensação de que os gestores acreditam que a implementação do equipamento prescinde justificas.

\section{REFERÊNCIAS}

AMIEL, Tel; AMARAL, Sergio Ferreira do. Nativos e imigrantes: Questionando o conceito de Fluência Tecnológica Docente. Revista Brasileira de Informática da Educação, Campinas, SP, v. 21, n. 3, p.1-11, dez. 13. Disponível em: < http://goo.gl/oUoOTc>. Acesso em: 14 abr. 2014.

BASTOS, Maria Helena Camara. Do quadro negro à lousa digital: a história de um dispositivo escolar. Caderno de História da Educação, Uberlândia, n. 4, p.133-141, 01 jan. 2005 .

BELSON, David. Akamai Technologies (Org.). The state of the Internet, v.8, n.2, jun. 2015. Disponível em: <www.stateoftheinternet.com>. Acesso em: 03 ago. 2015.

BRAGA, Denise Bértoli. Ambientes digitais: reflexões teóricas e práticas. São Paulo: Cortez Editora, 2013. 148 p. 
CARRERI, Andréa Varsone. Cotidiano escolar e políticas curriculares: táticas entre professores consumidores. 2007. 131 f. Dissertação (Mestrado em Educação) - Faculdade de Educação, Universidade Estadual de Campinas, Campinas, SP, 2007.

CASTELLS, Manuel; MAJER, Roneide Venâncio; GERGARDT, Klauss Brandini. A sociedade em rede. 10. ed. São Paulo: Paz e Terra, 2000.

CERTEAU, Michel de. A invenção do cotidiano: 1. Artes de Fazer. 9. ed. Petrópolis: Vozes, 2003.

GARCÍA, Francisco García; FERNANDEZ, Rogério Garcia; SOUZA, Karla Isabel de. Lousa digital interativa: avaliação da interação didática e proposta de aplicação de narrativa audiovisual. Etd: Educação Temática Digital, Campinas, SP, v. 12, n., p.92-111, 01 mar. 2011. Disponível em: < http://periodicos.sbu.unicamp.br/ojs/index.php/etd/issue/view/107> . Acesso em: 03 Ago. 2015.

LÉVY, Pierre. As tecnologias da inteligência: o futuro do pensamento na era da informática. São Paulo. Ed. 34, 1993. 206p.

MANOVICH, Lev. The language of new media. London: The Mit Press Cambridge, 2001. $354 \mathrm{p}$.

MATTAR, Maria Eduarda. Guias das cidades digitais. 2008. Disponível em:

< http://goo.gl/H30vuF>. Acesso em: 01 nov. 2013.

NAKASHIMA, Rosária Helena Ruiz. A linguagem interativa da lousa digital e a teoria dos estilos de aprendizagem. 2008. 160 f. Dissertação (Mestrado) - Departamento de Faculdade de Educação, Unicamp, Campinas, SP, 2008.

PETRUCCI-ROSA, Maria Inês; CARRERI, A. V.; RAMOS, T. A. Formação docente no ensino médio: táticas curriculares na disciplina escolar Química. In: Maria Inês PetrucciRosa, Adriana V. Rossi. (Org.). Educação Química no Brasil: memórias, políticas e tendências. 2. ed. Campinas, SP: Editora Átomo, 2012, v. 1, p. 105-125.

SILVA, Francisco Mendes da. Aspectos relevantes das novas tecnologias aplicadas à educação e os desafios impostos para a atuação dos docentes. Revista de Ciências Humanas da UNIPAR, v.11, n.2, p.75-81, abril/jun. 2003.

\section{Como citar este documento:}

ALMEIDA, José Adolfo Mota de; PINTO NETO, Pedro da Cunha. A lousa digital interativa: táticas e astúcias de professores consumidores de novas tecnologias. ETD - Educação Temática Digital, Campinas, SP, v. 17, n. 2, p. 394-413, ago. 2015. ISSN 1676-2592. Disponível em: <http://periodicos.sbu.unicamp.br/ojs/index.php/etd/article/view/8636465>. Acesso em: 28 ago. 2015. 